\title{
Adherence to and satisfaction with low-intensity physical activity and supervised moderate-high intensity exercise during chemotherapy for breast cancer
}

\section{Author(s)}

van Waart, Hanna; Buffart, Laurien M.; Stuiver, Martijn M.; van Harten, Wim H.; Sonke, Gabe S.; Aaronson, Neil K.

\section{DOI}

10.1007/s00520-019-05019-1

\section{Publication date}

2020

Document Version

Author accepted manuscript (AAM)

\section{Published in}

Supportive care in cancer : official journal of the Multinational Association of Supportive Care in Cancer

\section{Link to publication}

\section{Citation for published version (APA):}

van Waart, H., Buffart, L. M., Stuiver, M. M., van Harten, W. H., Sonke, G. S., \& Aaronson, N. K. (2020). Adherence to and satisfaction with low-intensity physical activity and supervised moderate-high intensity exercise during chemotherapy for breast cancer. Supportive care in cancer : official journal of the Multinational Association of Supportive Care in Cancer, 28, 2115-2126. https://doi.org/10.1007/s00520-01905019-1

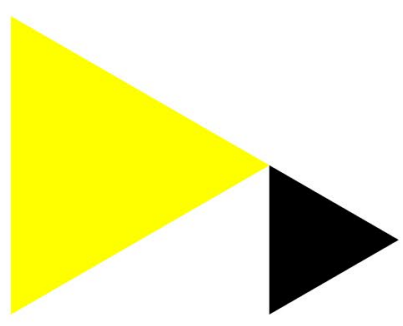




\title{
Adherence to and satisfaction with low-intensity physical activity and supervised moderate-high intensity exercise during chemotherapy for breast cancer
}

\author{
Hanna van Waart ${ }^{1}$ • Laurien M. Buffart ${ }^{2,3}$ - Martijn M. Stuiver ${ }^{4,5}$ • Wim H. van Harten ${ }^{1,6} \cdot$ Gabe S. Sonke $^{7}$. \\ Neil K. Aaronson ${ }^{1}$
}

Received: 24 March 2019 / Accepted: 30 July 2019

(C) Springer-Verlag GmbH Germany, part of Springer Nature 2019

\begin{abstract}
Purpose In this study, we investigated factors associated with program adherence and patient satisfaction with a home-based physical activity program (Onco-Move, $N=77$ ) and a supervised exercise program with a home-based component (OnTrack, $N=76)$.

Methods We assessed adherence via self-report (home-based program) and attendance records (supervised program). We used logistic regression analysis to identify sociodemographic, clinical and behavioural variables associated with program adherence. Patient satisfaction was assessed with self-report and is reported descriptively.

Results Fifty-one percent of Onco-Move and 62\% of OnTrack participants were adherent to the home-based program, while 59\% of OnTrack participants were adherent to the supervised sessions. Higher baseline physical fitness was associated with higher adherence to home-based components. Higher disease stage and having a partner were associated with adherence to OnTrack supervised sessions. Overall satisfaction with the exercise programs was high, but ratings of coaching provided by professionals for the home-based components were low. Patients offered suggestions for improving delivery of the programs.

Conclusions These findings point to factors relevant to program adherence and suggest ways in which such programs can be improved. Providing additional time and training for health care professionals could improve the quality and hopefully the effectiveness of the interventions. The use of online diaries and smartphone apps may provide additional encouragement to participants. Finally, allowing greater flexibility in the planning and availability of supervised exercise training in order to accommodate the variability in cancer treatment schedules and the (acute) side effects of the treatments could also enhance program adherence.
\end{abstract}

Trial registration Netherlands Trial Register, NTR2159.

http://www.trialregister.nl/trialreg/admin/rctview.asp?TC=2159

Keywords Adherence $\cdot$ Patient satisfaction $\cdot$ Physical activity $\cdot$ Exercise $\cdot$ Breast cancer $\cdot$ Chemotherapy

Neil K. Aaronson

n.aaronson@nki.nl

1 Division of Psychosocial Research and Epidemiology, The Netherlands Cancer Institute, Plesmanlaan 121, 1066 CX Amsterdam, The Netherlands

2 Departments of Epidemiology and Biostatistics and Medical Oncology, the Amsterdam Pubic Health research institute and Cancer Center, Amsterdam University Medical Centers, Amsterdam, The Netherlands

3 Exercise Medicine Research Institute, Edith Cowan University, Joondalup, Australia
4 Center for Quality of Life, The Netherlands Cancer Institute, Amsterdam, The Netherlands

5 ACHIEVE Center for Applied Research, Faculty of Health, Amsterdam University of Applied Science, Amsterdam, The Netherlands

6 Department of Health Technology and Services Research, University of Twente, Enschede, The Netherlands

7 Department of Medical Oncology, The Netherlands Cancer Institute, Amsterdam, The Netherlands 


\section{Introduction}

Exercise has beneficial effects for patients with cancer undergoing chemotherapy. It may limit fatigue, help to maintain physical fitness and function, reduce side effects such as nausea and pain and improve chemotherapy completion rates $[1$, 2]. Rates of cancer patients' adherence to exercise programs range from 54 to $78 \%$ [3]. Effectiveness and costeffectiveness of exercise programs could be enhanced by improving adherence to such programs $[4,5]$. This requires better understanding of the factors associated with adherence.

Previous studies in patients with cancer have described various factors associated with adherence to either supervised $[6,7]$ or home-based $[8,9]$ exercise programs. A consistent finding is the association between pre-illness exercise history and adherence [3]. Other associated factors in at least some studies include having a partner [8], higher education [10], low body mass index [10], a more advanced disease stage $[6,9]$, not receiving radiotherapy [10], being less depressed $[6]$, less fatigued $[8,10]$, having better cardiovascular fitness $[6,8]$, better physical functioning [7] and motivational factors [11].

As described by the theory of planned behaviour [12], motivational factors, including attitudes, subjective norms, perceived self-efficacy and perceived benefits and barriers, can help to explain exercise behaviour [3]. Also, sociodemographic and clinical variables, physical fitness and psychosocial factors such as health-related quality of life may influence program adherence [3]. Additionally, satisfaction with exercise programs can provide leads to improving adherence rates. To date, the few studies that have investigated factors associated with exercise adherence during chemotherapy have yielded inconsistent findings. More insight is needed into determinants of adherence to different exercise modalities during chemotherapy [3].

In this paper, we used data from the physical exercise during adjuvant chemotherapy effectiveness study (PACES) [1], a randomized controlled trial that compared the effects of a home-based physical activity program (Onco-Move) and a supervised exercise program with a home-based component (OnTrack) to usual care in patients undergoing adjuvant chemotherapy. The aims of the present analyses were to (1) identify factors associated with adherence and (2) evaluate patients' satisfaction with and their suggestions for further improvement of the programs.

\section{Methods}

\section{Study procedures and participants}

Details have been reported elsewhere [13]. Briefly, we invited patients with breast or colon cancer aged $\geq 18$ years, who were scheduled for adjuvant chemotherapy with curative intent, with no comorbid conditions that would contraindicate participation in an exercise program. For assessment purposes, participants had to be fluent in Dutch. The current paper focuses on patients with breast cancer, who represented the large majority of participants $(91 \%)$.

After informed consent, participants were randomized to Onco-Move, OnTrack or usual care using the minimization method, resulting in balanced groups with respect to age, diagnosis, treating hospital and use of trastuzumab. Institutional review boards of all participating hospitals approved the study (primary: Netherlands Cancer Institute, PTC09.2711).

\section{Interventions}

Onco-Move is a home-based, low intensity, self-managed physical activity program with behavioural reinforcement [13]. Trained nurses encouraged participants to be physically active $30 \mathrm{~min} /$ day, 5 days/week, at an intensity level 12 to 14 on the Borg Scale of perceived exertion [13]. Participants received written information, including a motivational poster based on their exercise stage according to the transtheoretical model [14], and were encouraged to keep an activity diary to be discussed at each chemotherapy cycle. In this diary, patients recorded the type, duration and intensity of their activities.

OnTrack is a moderate-high intensity, combined resistance and aerobic exercise program, supervised by trained physiotherapists [13]. The program included twice weekly resistance exercises of six large muscle groups with two series of eight repetitions at $80 \%$ of one-repetition maximum, followed by $30 \mathrm{~min}$ of aerobic exercises with an intensity of $50 \%$ to $80 \%$ of the maximal workload estimated by the steep ramp test [15]. Participants were also encouraged to be physically active in the Onco-Move manner, including use of a diary. Both interventions started with the first cycle of chemotherapy and continued until 3 weeks after the last cycle.

\section{Adherence}

Adherence to home-based physical activity in Onco-Move and OnTrack was calculated as the number of active days reported in the diary divided by the number of active days prescribed (5 days/week) over the course of the chemotherapy treatment. A participant was considered adherent when physically active for at least $30 \mathrm{~min}$ on at least $75 \%$ of the prescribed days [1].

Adherence to OnTrack supervised sessions was calculated as the number of sessions attended divided by the number of sessions expected (twice a week) over the course of the chemotherapy treatment. A participant was considered adherent when attending at least $75 \%$ of the prescribed sessions [1]. 
The physiotherapists recorded patients' reasons for not attending supervised sessions. Two independent researchers (HvW and LB) categorized these reasons. Differences were discussed until consensus was reached.

\section{Factors potentially associated with adherence}

All factors potentially associated with adherence were assessed at baseline. Sociodemographic variables assessed by questionnaire [13] included age at baseline (in years), education $(0=$ low/intermediate (high school or less), $1=$ high (college or university degree) $)$, marital status $(0=$ no partner, $1=$ partner $)$ and work situation $(0=$ no paid employment, $1=$ paid employment).

Clinical variables retrieved from medical records included cancer stage $(0=$ stage I/II, $1=$ stage III), type of surgery $(0=$ mastectomy, $1=$ breast-conserving), axillary lymph node dissection $(0=$ no, $1=$ yes $)$, chemotherapy with taxanes $(0=$ no, $1=$ yes $)$, use of trastuzumab ( $0=$ no, $1=$ yes $)$ and radiotherapy $(0=$ no, $1=$ yes $)[13]$. More than $92 \%$ of the participants received anthracyclines as part of their chemotherapy, resulting in insufficient variability to investigate its potential association with program adherence.

Physical factors included baseline cardiorespiratory fitness assessed with the steep ramp test [15] and endurance test [13], and muscle strength assessed with a handheld dynamometer for elbow flexion [16] and knee extension [17].

Psychosocial factors included general and physical fatigue (MFI) [18], global quality of life (EORTC QLQ-C30 questionnaire) [19] and anxiety and depression (Hospital Anxiety and Depression Scale; HADS) [20].

Exercise stage was based on the transtheoretical model [14]. Participants were categorized as non-regular exercisers $(0=$ pre-contemplation, contemplation and preparation $)$ or regular exercisers ( $1=$ action and maintenance phase).

Questions based on the theory of planned behaviour [21] assessed physical activity-related self-efficacy (five items, 0 10 response scale), perceived social support (seven items, 5point Likert-type response scale), perceived barriers to (13 items) and benefits of (12 items) physical activity and attitude towards physical activity (7-point adjective rating response scales). All scales are described in detail elsewhere [22].

\section{Satisfaction with Onco-Move and OnTrack}

At completion of both programs, participants rated their satisfaction with program quality, logistics and guidance on $0-10$ response scales (see tables in result section for all questions). Additionally, open-ended questions asked for three positive and negative points and suggestions for improvement. Two researchers (HvW and LB) independently categorized these comments. Differences were discussed until consensus was reached.

\section{Statistical analyses}

Descriptive statistics were used to characterize adherence to and satisfaction with both programs. Since adherence data were skewed, and to facilitate clinically meaningful interpretation, we dichotomized adherence (adherent $\geq 75 \%$ of prescription) [1].

We used univariable and multivariable logistic regression analyses to investigate sociodemographic, clinical, physical, psychosocial and motivational factors associated with adherence $(0=$ no, $1=$ yes $)$. Due to the large number of potential correlates, we used forward selection. Variables that significantly improved the model were added one-by-one using the likelihood ratio test. Odds ratios (OR) and 95\% Confidence Intervals (CI) are reported. We evaluated the discriminative ability of the models using the area under the receiver operating characteristic curve (AUC).

\section{Results}

Participant flow through the study is reported in detail elsewhere [1]. Briefly, we randomized 230 of 524 eligible patients (44\%) to Onco-Move (77), OnTrack (76) or usual care (77). Participants' baseline characteristics were balanced across groups (Table 1).

\section{Adherence}

Thirty-nine (51\%) Onco-Move and 47 (62\%) OnTrack participants were adherent to the home-based program, and 45 (59\%) of OnTrack participants were adherent to the supervised sessions (Table 2).

Feeling too ill was the most frequently reported reason for not attending supervised sessions (53\%, Table 2). About onethird of the missed sessions were due to logistical reasons (participants' personal scheduling problems (16\%), scheduling conflict with planned chemotherapy session (10\%) or closed physiotherapy practice due to public holidays (5\%)).

\section{Factors associated with exercise adherence}

In the univariable analyses, higher baseline endurance time and a more positive attitude towards exercise during chemotherapy were significantly and positively associated with adherence to Onco-Move (Table 3). In the multivariable regression analyses, only baseline endurance time remained significant $(\mathrm{OR}=1.10,95 \% \mathrm{CI} 1.03-1.17, \mathrm{AUC}=0.68)$.

In the univariable and multivariable analysis, only higher baseline endurance time $(\mathrm{OR}=1.08,95 \% \mathrm{CI}=1.02 ; 1.15$, AUC $=0.71)$ was significantly associated with adherence to the home-based component of OnTrack. 
Table 1 Baseline sociodemographic and clinical characteristics of participants

\begin{tabular}{|c|c|c|c|}
\hline & $\begin{array}{l}\text { Total } \\
N=153\end{array}$ & $\begin{array}{l}\text { OnTrack } \\
N=76\end{array}$ & $\begin{array}{l}\text { Onco-Move } \\
N=77\end{array}$ \\
\hline Age mean years (SD) & $50.2(9.3)$ & $49.9(8.4)$ & $50.5(10.1)$ \\
\hline Gender $N$ female (\%) & $151(99 \%)$ & $74(97 \%)$ & $77(100 \%)$ \\
\hline \multicolumn{4}{|l|}{ Marital status $N(\%)$} \\
\hline Single/divorced/widowed & $35(23 \%)$ & $18(24 \%)$ & $17(22 \%)$ \\
\hline Married/living together & $118(77 \%)$ & $58(76 \%)$ & $60(78 \%)$ \\
\hline \multicolumn{4}{|l|}{ Education $N(\%)$} \\
\hline Low/intermediate & $65(42 \%)$ & $30(39 \%)$ & $35(45 \%)$ \\
\hline High (college/university) & $88(58 \%)$ & $46(61 \%)$ & $42(54 \%)$ \\
\hline \multicolumn{4}{|l|}{ Work $N(\%)$} \\
\hline Paid employment & $104(68 \%)$ & $53(70 \%)$ & $51(66 \%)$ \\
\hline No paid employment & $49(32 \%)$ & $23(30 \%)$ & $26(34 \%)$ \\
\hline \multicolumn{4}{|l|}{ Cancer stage $N(\%)$} \\
\hline Stage I and II & $79(52 \%)$ & $37(49 \%)$ & $42(55 \%)$ \\
\hline Stage III & $74(48 \%)$ & $39(51 \%)$ & $35(45 \%)$ \\
\hline \multicolumn{4}{|l|}{ Cancer treatment $N(\%)$} \\
\hline Breast conserving surgery & $118(77 \%)$ & $56(74 \%)$ & $62(81 \%)$ \\
\hline Axillary lymph node dissection & $42(27 \%)$ & $24(32 \%)$ & $18(23 \%)$ \\
\hline Radiotherapy & $120(78 \%)$ & $60(79 \%)$ & $60(78 \%)$ \\
\hline \multicolumn{4}{|l|}{ Chemotherapy mean (SD) } \\
\hline Prescribed chemotherapy days & 119.6 & 119.2 & 119.9 \\
\hline Actual chemotherapy days & $107.5(32.1)$ & $110.8(28.6)$ & $104.3(35.6)$ \\
\hline \multicolumn{4}{|l|}{ Exercise stage $N(\%)$} \\
\hline Pre-contemplation & $1(1 \%)$ & $1(1 \%)$ & $0(0 \%)$ \\
\hline Contemplation & $26(17 \%)$ & $11(14 \%)$ & $15(19 \%)$ \\
\hline Preparation & $38(25 \%)$ & $15(20 \%)$ & $23(30 \%)$ \\
\hline Action & $4(3 \%)$ & $2(3 \%)$ & $2(3 \%)$ \\
\hline Maintenance & $84(55 \%)$ & $47(62 \%)$ & $37(48 \%)$ \\
\hline
\end{tabular}

In the univariable (Table 3) and multivariable regression analyses, both a higher disease stage $(\mathrm{OR}=4.90,95 \% \mathrm{CI}=$ $1.66 ; 14.43)$ and having a partner $(\mathrm{OR}=5.08,95 \% \mathrm{CI}=1.37$; $18.83)$ were significantly and independently associated with adherence to the OnTrack supervised sessions $(\mathrm{AUC}=0.55)$.

No other clinical, motivational or psychosocial variables were associated significantly with adherence to either OncoMove or OnTrack.

\section{Satisfaction with Onco-Move}

On average, satisfaction with Onco-Move was 7.4 out of 10 (Table 4). The average rating for "Would you recommend this program to fellow patients?" was 8.2. The diary was rated with a 7.6, while encouragement received was rated 5.5 for usefulness and 5.1 for quality.

In total, 120 positive comments, 53 negative comments and 23 suggestions for improving Onco-Move were given (Table 5). The most frequent positive remarks pertained to the program's motivational elements, benefits derived from being physically active and information provided on the benefits of and ways to be physical active during chemotherapy. Negative comments included lack of encouragement and support, burdensomeness of the daily diary and the resulting feelings of guilt if unable to be physically active. The most frequent suggestions for program improvement were to add more encouragement and support, to facilitate group physical activity, to complete the diary digitally (e.g. via an app) and to add more variation to the program (Tables 5 and 6).

\section{Satisfaction with OnTrack}

The average satisfaction score with OnTrack was 8.2 out of 10 (Table 4). Average score for "Would you recommend this program to fellow patients?" was 9.4. The location and quality of the supervised training received 7.9 for aerobic and 7.8 for strength training. The experienced intensity of the aerobic and strength training was rated as 6.5 and 6.2 , respectively. The 
Table 2 Adherence to homebased and supervised exercise programs and reasons for not attending supervised sessions

\begin{tabular}{|c|c|c|}
\hline & $\begin{array}{l}\text { Onco-Move } \\
(N=77)\end{array}$ & $\begin{array}{l}\text { OnTrack } \\
(N=76)\end{array}$ \\
\hline \multicolumn{3}{|l|}{ Home-based physical activity } \\
\hline Number of participants adherent ${ }^{\mathrm{a}} N(\%)$ & $39(51 \%)$ & $47(62 \%)$ \\
\hline Average percentage of 5 days activity ${ }^{\mathrm{b}}$ Mean (SD) & $64 \%(27 \%)$ & $62 \%(24 \%)$ \\
\hline Average percentage of 5 days activity ${ }^{\mathrm{b}}$ [range] & {$[2-104 \%]$} & [1-99\%] \\
\hline \multicolumn{3}{|l|}{ OnTrack supervised sessions } \\
\hline Number of participants adherent ${ }^{\mathrm{c}} N(\%)$ & & $45(59 \%)$ \\
\hline Average percentage of attended sessions ${ }^{\mathrm{d}}$ Mean (SD) & & $71 \%(21 \%)$ \\
\hline Average percentage of attended sessions ${ }^{\mathrm{d}}$ [range] & & {$[6 \%-100 \%]$} \\
\hline Total missed OnTrack supervised sessions ${ }^{\mathrm{e}}$ & & $797(100 \%)$ \\
\hline Felt too ill & & $424(53 \%)$ \\
\hline Logistic reasons ${ }^{\mathrm{f}}$ & & $241(30 \%)$ \\
\hline Logistic reasons participant & & $125(16 \%)$ \\
\hline Holiday participant & & $74(9 \%)$ \\
\hline Hospital appointment & & $13(2 \%)$ \\
\hline Work & & $11(1 \%)$ \\
\hline Other priorities & & $10(1 \%)$ \\
\hline family emergencies & & $9(1 \%)$ \\
\hline Lack of transportation & & $4(1 \%)$ \\
\hline Time mix-up & & $4(1 \%)$ \\
\hline Chemotherapy admission & & $80(10 \%)$ \\
\hline Public Holiday & & $36(5 \%)$ \\
\hline Reason not specified & & $132(17 \%)$ \\
\hline Drop-out & & $92(12 \%)$ \\
\hline Unknown & & $40(5 \%)$ \\
\hline
\end{tabular}

${ }^{\text {a }}$ More than $75 \%$ of time active for 30 min for 5 days a week

${ }^{\mathrm{b}}$ Number of active days reported in the diary divided by the number of active days prescribed ( 5 days a week) over the course of the chemotherapy treatment

${ }^{\mathrm{c}}$ More than $75 \%$ of sessions attended

${ }^{\mathrm{d}}$ Number of sessions attended divided by the number of sessions expected (twice a week) over the course of the chemotherapy treatment.

${ }^{\mathrm{e}}$ Out of 2832 planned sessions

${ }^{\mathrm{f}}$ The category 'Logistical reasons' is subdivided in 'Logistical reasons participant', 'Chemotherapy admission in hospital' and 'Public Holiday'. The category 'Logistical reasons participants' is again subdivided in seven reasons home-based component received an average satisfaction score of 6.6 for the diary, 5.0 for the motivational poster, 5.0 for usefulness and 3.2 for quality of encouragement.

In total, 102 positive comments, 40 negative comments and 31 suggestions for improving OnTrack were given (Table 6). Positive remarks included the benefits of being physically active, quality of the supervision and structure provided by the program. Negative remarks included triggering negative feelings when not able to attend a session, time investment required, lack of continuity of supervision and lack of discussion of the diary. Suggestions to improve OnTrack included more one-on-one supervision, more opportunities to train and interact with other cancer patients, better discussion of the diary, more variation in exercises, locations closer to participant's home and more flexibility in timing of training (e.g. other training moments, but also the possibility of starting the program directly after surgery and/or continuing the program after chemotherapy ends).

\section{Discussion}

Our analyses yielded three key findings. First, patients with higher levels of baseline physical fitness were more likely to adhere to the home-based components. This may reflect exercise history, which is a well-documented predictor of adherence [3]. However, baseline physical fitness was not associated significantly with adherence to supervised exercise. It may be harder for patients with lower levels of physical fitness to be physically active on their own. These patients may 
Table 3 Predictors of adherence: sociodemographic, clinical, physical fitness, psychosocial and motivational factors

\begin{tabular}{|c|c|c|c|}
\hline & $\begin{array}{l}\text { Onco-Move } \\
\text { Home-based } \\
\text { OR }(95 \% \mathrm{CI})\end{array}$ & $\begin{array}{l}\text { OnTrack } \\
\text { Home-based } \\
\text { OR }(95 \% \mathrm{CI})\end{array}$ & $\begin{array}{l}\text { OnTrack } \\
\text { Session attendance } \\
\text { OR }(95 \% \mathrm{CI})\end{array}$ \\
\hline \multicolumn{4}{|l|}{ Sociodemographics } \\
\hline Age, years & $0.97(0.93-1.02)$ & $0.98(0.92-1.03)$ & $0.98(0.93-1.04)$ \\
\hline Partner $^{\mathrm{a}}$ & $0.70(0.23-2.09)$ & $1.04(0.35-3.09)$ & $2.99(1.00-8.89)^{*}$ \\
\hline High education $^{\mathrm{b}}$ & $2.00(0.80-5.02)$ & $1.43(0.56-3.68)$ & $1.88(0.73-4.79)$ \\
\hline Paid work ${ }^{\mathrm{a}}$ & $1.62(0.62-4.26)$ & $1.38(0.51-3.73)$ & $1.17(0.44-3.16)$ \\
\hline \multicolumn{4}{|l|}{ Clinical } \\
\hline More advanced disease stage ${ }^{\mathrm{c}}$ & $0.66(0.26-1.67)$ & $1.75(0.69-4.47)$ & $4.43(1.65-11.89)^{*}$ \\
\hline Breast-conserving surgery $^{\mathrm{a}}$ & $1.10(0.35-3.53)$ & $1.11(0.39-3.16)$ & $0.39(0.12-1.20)$ \\
\hline Axillary lymph node dissection ${ }^{\mathrm{a}}$ & $2.58(0.80-8.29)$ & $1.04(0.38-2.83)$ & $0.95(0.36-2.53)$ \\
\hline Radiotherapy $^{\mathrm{a}}$ & $2.08(0.65-6.59)$ & $0.39(0.13-1.20) \#$ & $0.86(0.28-2.61)$ \\
\hline Taxane use $^{\mathrm{a}}$ & $2.58(0.89-7.49) \#$ & $1.25(0.43-3.59)$ & $1.43(0.50-4.08)$ \\
\hline Trastuzumab use $^{\mathrm{a}}$ & $1.38(0.48-3.93)$ & $0.74(0.24-2.28)$ & $1.19(0.38-3.70)$ \\
\hline \multicolumn{4}{|l|}{ Physical fitness } \\
\hline Maximal short exercise capacity, watts & $1.01(1.00-1.02) \#$ & $1.01(1.00-1.02)$ & $1.01(1.00-1.02)$ \\
\hline Endurance time, minutes & $1.10(1.03-1.17)^{*}$ & $1.08(1.02-1.15)^{*}$ & $1.02(0.97-1.08)$ \\
\hline HHD elbow flexion, $\mathrm{Nm}$ & $1.00(0.99-1.01)$ & $1.00(0.99-1.01)$ & $1.00(0.99-1.01)$ \\
\hline HHD knee extension, Nm & $1.01(1.00-1.01)$ & $1.00(1.00-1.01)$ & $1.00(0.99-1.01)$ \\
\hline \multicolumn{4}{|l|}{ Psychosocial factors } \\
\hline General Fatigue & $0.99(0.87-1.11)$ & $1.09(0.97-1.22)$ & $0.92(0.82-1.04)$ \\
\hline Physical Fatigue & $1.03(0.91-1.18)$ & $1.00(0.89-1.12)$ & $0.90(0.80-1.02) \#$ \\
\hline Overall quality of life & $0.97(0.94-1.01)$ & $1.00(0.97-1.03)$ & 1.03 (1.00-1.07) \# \\
\hline Anxiety & $1.05(0.89-1.24)$ & $1.06(0.92-1.22)$ & $0.95(0.81-1.11)$ \\
\hline Depression & $1.04(0.87-1.25)$ & $1.04(0.90-1.19)$ & $0.95(0.80-1.12)$ \\
\hline \multicolumn{4}{|l|}{ Motivational variables } \\
\hline Exercise stage $^{\mathrm{d}}$ & $1.62(0.65-4.03)$ & $0.73(0.27-1.94)$ & $0.78(0.30-2.06)$ \\
\hline Self-efficacy & $1.14(0.87-1.50)$ & $1.23(0.92-1.67)$ & $0.98(0.74-1.31)$ \\
\hline Social support & $2.08(0.88-4.90) \#$ & $0.46(0.17-1.20)$ & $0.53(0.21-1.36)$ \\
\hline Benefits & $1.05(0.55-2.01)$ & $1.49(0.64-3.50)$ & $0.69(0.30-1.61)$ \\
\hline Barriers & $1.12(0.48-2.63)$ & $0.37(0.13-1.02) \#$ & $0.76(0.29-1.97)$ \\
\hline Attitude & $2.55(1.07-6.10)^{*}$ & $0.86(0.36-2.06)$ & $0.77(0.32-1.84)$ \\
\hline
\end{tabular}

\footnotetext{
${ }^{*}$, \# Significant difference: $* p<0.05 ; \# 0.10<p<0.05$

OR odds ratio, $95 \%$ CI 95\% confidence interval, $H D D$ handheld dynamometer

${ }^{\mathrm{a}} 0=$ no, $1=$ yes

${ }^{\mathrm{b}} 0=$ low/intermediate, $1=$ high

${ }^{\mathrm{c}} 0=$ stage I/II, $1=$ stage III

${ }^{\mathrm{d}} 0=$ non-regular exercisers, $1=$ regular exercisers
}

therefore benefit from and be more motivated by the structure provided by a supervised program.

Our trial started after patients had undergone surgery and, in most cases, radiotherapy. Previous studies have reported a decline in physical fitness and functioning levels after surgery and/or radiotherapy [23]. Given the finding that baseline physical fitness (i.e. endurance time) is associated positively with exercise adherence, improving or minimizing loss of physical fitness prior to chemotherapy could enhance adherence to the home-based programs. An early start of physical activity programs directly after diagnosis might thus be beneficial in this regard.

Second, participants with a higher disease stage and with a partner were more likely to adhere to the supervised OnTrack sessions. It is somewhat puzzling why participants with a higher disease stage are more likely to adhere. Although this might be a chance finding, we are not the first to report it [6, 9]. Perhaps, these patients are more open to or in need of this type of supervised exercise. Qualitative research comparing potential differences in desired encouragement, experienced 
Table 4 Patients' evaluations of Onco-Move and OnTrack programs
Onco-Move

Mean (SD)

OnTrack

Mean (SD)

Overall

How do you rate the program?

$7.4(1.4)$

$8.2(1.2)$

Did the program meet you expectations?

$7.1(1.8)$

$8.2(1.6)$

Would you recommend this program to fellow patients?

$8.2(2.1)$

$9.4(1.3)$

Home-based

How useful was the diary?

$7.6(2.0)$

$6.6(2.2)$

How useful was the motivation poster?

$5.9(2.4)$

$5.0(2.3)$

How useful was the information booklet?

How useful was the encouragement to an active lifestyle?*

Were you satisfied with the quality of the encouragement?*

Supervised sessions

Logistics

How do you rate the proximity of the training location?

How do you rate the services at the training location?

How do you rate the ambiance at the training location?

Could you plan the training sessions in your daily life?

Training

How do you rate the supervision?

$7.2(1.9)$

$5.5(2.6)$

$5.0(2.5)$

$5.1(2.5)$

$3.2(1.6)$

$8.3(1.4)$

$7.8(1.0)$

$8.5(1.1)$

$7.6(2.0)$

$8.4(1.2)$

Quality of aerobic training

$7.9(1.2)$

Quality of strength training

$7.8(1.1)$

Intensity of aerobic training

$6.5(1.6)$

Intensity of strength training

$6.2(1.4)$

$8.5(1.8)$

$5.8(2.1)$

$N(\%)$

$N(\%)$

Was the home-based part discussed?

Yes, every 3 weeks

$9(12 \%)$

$18(24 \%)$

Yes, but less than every 3 weeks

$4(5 \%)$

No never

$37(48 \%)$

$9(12 \%)$

Home-based sessions: did you exercise alone or with somebody?

$10(13 \%)$

$35(46 \%)$

Always alone

$17(22 \%)$

Sometimes with somebody else

$4(5 \%)$

Supervised sessions: did you exercise alone or with somebody?

Always alone

$11(15 \%)$

With other patients with cancer

$47(62 \%)$

With other patients

$9(12 \%)$

How was the timing of the training sessions?

Too early

Just right

Too late

$14(18 \%)$

How long did the fatigue last?

One day or less

Two days

Did you get an injury?

Note: All questions were posed on a $0-10$ scale, with the exception of * who were transformed from a $0-5$ to a 0 10 scale 
Table 5 Suggestions, positive and negative points for OncoMove

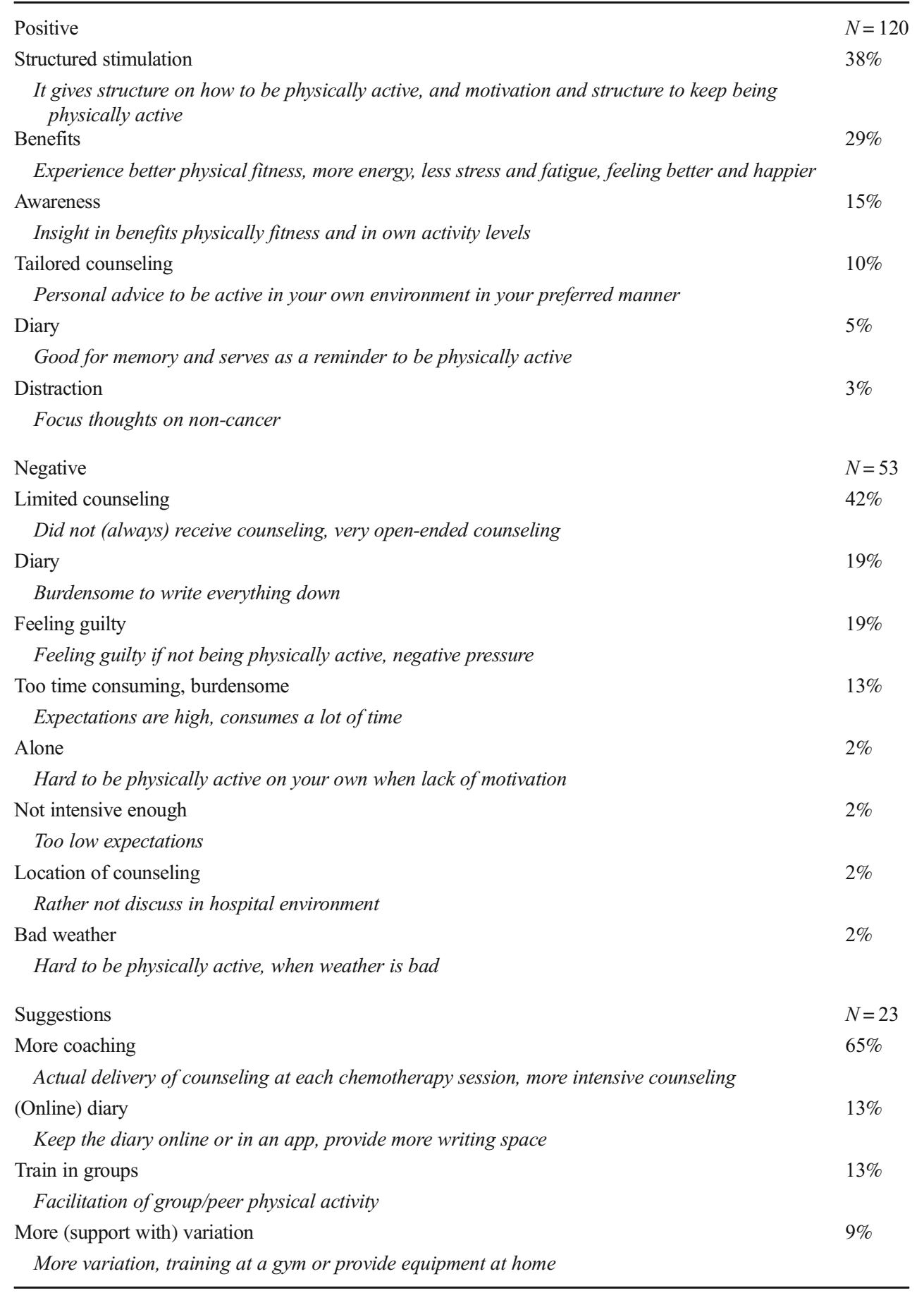

burden and benefits of supervised sessions between patients with higher and lower disease stage could provide more insight.

The association between having a partner and higher adherence has been reported previously [24, 25], frequently linking spousal social support to adherence. Interestingly, in our study, perceived social support was not associated significantly with adherence. This suggests that the role of the partner may have been more instrumental in nature.
Although frequently reported post-cancer treatment $[3,11$, 21], we found no significant association between motivational variables and adherence during active treatment [6-9]. Participants' motivation may potentially shift during chemotherapy. Patients might be unable to foresee what will motivate them during chemotherapy. Further research, preferably qualitative in nature, can hopefully provide leads as to why motivational variables are not associated with adherence to exercise programs during active treatment [22]. 
Table 6 Suggestions, positive and negative points for OnTrack
Positive

$N=102$

Benefits

$44 \%$

Experience better physical fitness, positive feeling, more energy, fulfillment, better appetite, confidence in and positive about your body

Supervision

Good supervision

Motivation

It gets you motivated to be physically active

Structure

Structure to the week, regularity

Contact with peers

Share experiences and knowledge with other patients

Awareness

Learn to tire yourself and benefits of physical fitness

Distraction

Focus thoughts on non-cancer

Negative

$N=40$

Burdensome

Burdensome directly after chemotherapy or when ill

Inadequate supervision

No discussion of the diary, lack of continuity of supervision

Difficulty with scheduling

Not enough flexibility to plan training, too early

Boring

Every week the same training, with little variation

Too time consuming

Time consuming program

Distance

Large distance to training location

Location services

Suboptimal training equipment, noisy environment

Confronting

Confronting to be a cancer patient

Alone

$3 \%$

Lack of peer contact

Suggestions

$N=31$

More variation

More variation in training, add yoga or aerobics

More personalized supervision

Keep one physiotherapist and/or better transferal between physiotherapist

Location (proximity, facilities)

Training location closer to home, better equipment, separate room

More contact with peers

Schedule time prior or after training session for social interaction, train with other cancer patients

More flexibility for training times

More groups and/or training sessions

Discussion of diary

Discussion of diary, online supervision home-based 
Third, although the overall satisfaction was relatively high, participants were less satisfied with the encouragement provided as part of the home-based program. This may reflect time constraints operating in a busy clinical setting. In addition, it may be that our half-day training for nurses and physiotherapists for the home-based program was insufficient. Additional time, and probably also training, is needed to ensure that these health care professionals can provide optimal levels of encouragement to patients. Use of Web-based diaries and smartphone apps might also be useful in providing additional motivational support to adhere to such programs $[26,27]$.

The most frequently reported reasons for not attending supervised sessions were related the schedule of and toxicities associated with chemotherapy. Patients suggested that adding more flexibility in timing of the sessions could improve adherence. It is important to maintain a balance between offering flexibility (i.e., more group or drop-in sessions), and ensuring sufficient one-to-one attention and program continuity [28]. Participants also suggested enhancing social interaction to improve adherence and satisfaction, for example, by building in time for social contact immediately prior to or following the training. Finally, building more variation into the exercise program could reduce boredom and thereby enhance adherence [29].

Several limitations of our study should be noted. First, we used diary-based, self-reported physical activity to assess adherence to the home-based component. This may have introduced social desirability bias, leading to over-reporting of physical activity.

Second, for the supervised session, we focused on session attendance as the measure of adherence, as we had insufficient information to assess compliance to the prescribed exercise intensities. Different factors may be associated with compliance (whether participants meet the prescribed exercise intensity) than with attendance [30].

Third, the generalizability of the predictors to the total population may be limited. In fact, we know from previous analyses [22] that the non-participants, who declined participation to this trial because they did not wish to exercise had lower level of education, were less likely to be working, reported more fatigue and lower health-related quality of life, had lower sense of self-efficacy, more negative attitudes towards exercise, less social support, and perceived fewer benefits and more barriers to exercising during treatment than trial participants. All these factors could be predictors of adherence itself [3].

Finally, the ability of the multivariable models to predict adherence was low to moderate. This suggests that other factors may help explain differences in adherence to exercise programs during chemotherapy. These may include environmental factors (i.e. the suitability of the environment for exercising) or external motivational factors (i.e. type of encouragement received) $[3,11]$.
Our study also has considerable strengths, including the randomized controlled trial context, the possibility of evaluating adherence to both home-based and supervised exercise programs during chemotherapy, the use of a theoretical model and the availability of an objective measure of adherence to the supervised sessions.

In conclusion, patients with lower baseline physical fitness levels are less adherent to a home-based program, while having a higher disease stage and a partner is associated with adherence to supervised sessions. Providing additional time and training for health care professionals could improve the quality and hopefully the effectiveness of the interventions. The use of online diaries and smartphone apps may provide additional encouragement to participants, leading to higher levels of adherence and better outcomes. Finally, allowing greater flexibility in the planning and availability of supervised exercise training in order to accommodate the variability in cancer treatment schedules and the (acute) side effects of the treatments could also enhance program adherence.

Acknowledgements We thank the Netherlands Comprehensive Cancer Organization for the development of the Onco-Move intervention, and the VU University Medical Center in Amsterdam, Motion Physiotherapy in Uithoorn, and The Netherlands Cancer Institute in Amsterdam for the development of the OnTrack intervention. The PACES trial is part of the A-CaRe Program. We thank the A-CaRe Clinical Research Group and all of the patients, oncologists, nurses and physical therapists who participated in the trial. We also thank Marianne de Maaker-Berkhof and Miranda Gerritsma for their contributions to the data collection and entry.

Funding statement This work was supported by the Alpe d'Huzes/ Dutch Cancer Society Grant No. ALPE-2009-4299, the CZ Fund, Zilveren Kruis Achmea, and the Comprehensive Cancer Centre of the Netherlands.

\section{Compliance with ethical standards}

Competing interests The authors declare that they have no competing interest.

Ethical approval All procedures performed in studies involving human participants were in accordance with the ethical standards of the institutional and/or national research committee (primary: Netherlands Cancer Institute, PTC09.2711) and with the 1964 Helsinki declaration and its later amendments or comparable ethical standards.

Informed consent Informed consent was obtained from all individual participants included in the study.

\section{References}

1. van Waart H, Stuiver MM, van Harten WH, Geleijn E, Kieffer JM, Buffart LM, de Maaker-Berkhof M, Boven E, Schrama J, Geenen MM, Meerum Terwogt JM, van Bochove A, Lustig V, van den Heiligenberg SM, Smorenburg CH, Hellendoorn-van Vreeswijk JAJH, Sonke GS, Aaronson NK (2015) Effect of low-intensity physical activity and moderate- to high-intensity physical exercise 
during adjuvant chemotherapy on physical fitness, fatigue, and chemotherapy completion rates: results of the PACES randomized clinical trial. J Clin Oncol 33:1918-1927. https://doi.org/10.1200/JCO. 2014.59.1081

2. Furmaniak AC, Menig M, Markes MH (2016) Exercise for women receiving adjuvant therapy for breast cancer. Cochrane Database Syst Rev. https://doi.org/10.1002/14651858.CD005001.pub3

3. Kampshoff CS, Jansen F, van Mechelen W, May AM, Brug J, Chinapaw MJM, Buffart LM (2014) Determinants of exercise adherence and maintenance among cancer survivors: a systematic review. Int J Behav Nutr Phys Act 11:80. https://doi.org/10.1186/ 1479-5868-11-80

4. Milne HM, Wallman KE, Gordon S, Courneya KS (2008) Effects of a combined aerobic and resistance exercise program in breast cancer survivors: a randomized controlled trial. Breast Cancer Res Treat 108:279-288. https://doi.org/10.1007/s10549-007-9602-z

5. van Waart H, van Dongen JM, van Harten WH, Stuiver MM, Huijsmans R, Hellendoorn-van Vreeswijk JAJH, Sonke GS, Aaronson NK (2017) Cost-utility and cost-effectiveness of physical exercise during adjuvant chemotherapy. Eur J Health Econ 19: 893-904. https://doi.org/10.1007/s10198-017-0936-0

6. Courneya KS, Segal RJ, Gelmon K et al (2008) Predictors of supervised exercise adherence during breast cancer chemotherapy. Med Sci Sports Exerc 40:1180-1187. https://doi.org/10.1249/ MSS.0b013e318168da45

7. Klepin HD, Danhauer SC, Tooze JA, Stott K, Daley K, Vishnevsky T, Powell BL, Mihalko SL (2011) Exercise for older adult inpatients with acute myelogenous leukemia: a pilot study. J Geriatr Oncol 2: 11-17. https://doi.org/10.1016/j.jgo.2010.10.004

8. Shang J, Wenzel J, Krumm S, Griffith K, Stewart K (2012) Who will drop out and who will drop in: exercise adherence in a randomized clinical trial among patients receiving active cancer treatment. Cancer Nurs 35:312-322. https://doi.org/10.1097/NCC. 0b013e318236a3b3

9. Swenson KK, Nissen MJ, Henly SJ (2010) Physical activity in women receiving chemotherapy for breast cancer: adherence to a walking intervention. Oncol Nurs Forum 37:321-330. https://doi. org/10.1188/10.ONF.321-330

10. Witlox L, Velthuis MJ, Boer JH, Steins Bisschop CN, Wall E, Meulen WJTM, Schröder CD, Peeters PHM, May AM (2019) Attendance and compliance with an exercise program during localized breast cancer treatment in a randomized controlled trial: the PACT study. PLoS One 14:e0215517. https://doi.org/10.1371/ journal.pone. 0215517

11. Husebø AML, Dyrstad SM, Søreide JA, Bru E (2013) Predicting exercise adherence in cancer patients and survivors: a systematic review and meta-analysis of motivational and behavioural factors. J Clin Nurs 22:4-21. https://doi.org/10.1111/j.1365-2702.2012. 04322.x

12. Ajzen I (1991) The theory of planned behavior. Organ Behav Hum Decis Process 50:179-211. https://doi.org/10.1016/0749-5978(91) 90020-T

13. van Waart H, Stuiver MM, van Harten WH, Sonke GS, Aaronson NK (2010) Design of the physical exercise during adjuvant chemotherapy effectiveness study (PACES): a randomized controlled trial to evaluate effectiveness and cost-effectiveness of physical exercise in improving physical fitness and reducing fatigue. BMC Cancer 10:673. https://doi.org/10.1186/1471-2407-10-673

14. Marcus BH, Selby VC, Niaura RS, Rossi JS (1992) Self-efficacy and the stages of exercise behavior change. Res Q Exerc Sport 63: 60-66. https://doi.org/10.1080/02701367.1992.10607557

15. de Backer IC, Schep G, Hoogeveen A, Vreugdenhil G, Kester AD, van Breda E (2007) Exercise testing and training in a cancer rehabilitation program: the advantage of the steep ramp test. Arch Phys Med Rehabil 88:610-616. https://doi.org/10.1016/j.apmr.2007.02. 013
16. van der Ploeg RJ, Fidler V, Oosterhuis HJ (1991) Hand-held myometry: reference values. J Neurol Neurosurg Psychiatry 54: 244-247. https://doi.org/10.1136/jnnp.54.3.244

17. Knols RH, Aufdemkampe G, de Bruin ED, Uebelhart D, Aaronson NK (2009) Hand-held dynamometry in patients with haematological malignancies: measurement error in the clinical assessment of knee extension strength. BMC Musculoskelet Disord 10:31. https:// doi.org/10.1186/1471-2474-10-31

18. Smets EMA, Garssen B, Bonke B, De Haes JCJM (1995) The multidimensional fatigue inventory (MFI) psychometric qualities of an instrument to assess fatigue. J Psychosom Res 39:315-325. https://doi.org/10.1016/0022-3999(94)00125-O

19. Aaronson NK, Ahmedzai S, Bergman B, Bullinger M, Cull A, Duez NJ, Filiberti A, Flechtner H, Fleishman SB, Haes JCJM, Kaasa S, Klee M, Osoba D, Razavi D, Rofe PB, Schraub S, Sneeuw K, Sullivan M, Takeda F (1993) The European Organization for Research and Treatment of Cancer QLQ-C30: a quality-of-life instrument for use in international clinical trials in oncology. JNCI J Natl Cancer Inst 85:365-376. https://doi.org/10. 1093/jnci/85.5.365

20. Zigmond AS, Snaith RP (1983) The hospital anxiety and depression scale. Acta Psychiatr Scand 67:361-370. https://doi.org/10. 1111/j.1600-0447.1983.tb09716.x

21. Courneya KS, Friedenreich CM (1999) Utility of the theory of planned behavior for understanding exercise during breast cancer treatment. Psychooncology 8:112-122. https://doi.org/10.1002/ (SICI)1099-1611(199903/04)8:2<112::AID-PON341>3.0.CO;2-L

22. van Waart H, van Harten WH, Buffart LM, Sonke GS, Stuiver MM, Aaronson NK (2016) Why do patients choose (not) to participate in an exercise trial during adjuvant chemotherapy for breast cancer? Psychooncology 25:964-970. https://doi.org/10.1002/pon.3936

23. Lakoski SG, Eves ND, Douglas PS, Jones LW (2012) Exercise rehabilitation in patients with cancer. Nat Rev Clin Oncol 9:288296. https://doi.org/10.1038/nrclinonc. 2012.27

24. Ballard-Barbash R, Friedenreich CM, Courneya KS, Siddiqi SM, McTiernan A, Alfano CM (2012) Physical activity, biomarkers, and disease outcomes in cancer survivors: a systematic review. J Natl Cancer Inst 104:815-840. https://doi.org/10.1093/jnci/djs207

25. Kalter J, Buffart LM, Korstjens I, van Weert E, Brug J, Verdonck-de Leeuw IM, Mesters I, van den Borne B, Hoekstra-Weebers JEHM, Ros WJG, May AM (2015) Moderators of the effects of groupbased physical exercise on cancer survivors' quality of life. Support Care Cancer 23:2623-2631. https://doi.org/10.1007/ s00520-015-2622-z

26. Short CE, Rebar A, James EL, Duncan MJ, Courneya KS, Plotnikoff RC, Crutzen R, Vandelanotte C (2017) How do different delivery schedules of tailored web-based physical activity advice for breast cancer survivors influence intervention use and efficacy? J Cancer Surviv 11:80-91. https://doi.org/10.1007/s11764-0160565-0

27. Kanera IM, Willems RA, Bolman CAW, Mesters I, Verboon P, Lechner L (2017) Long-term effects of a web-based cancer aftercare intervention on moderate physical activity and vegetable consumption among early cancer survivors: a randomized controlled trial. Int J Behav Nutr Phys Act 14:19. https://doi.org/10.1186/ s12966-017-0474-2

28. Courneya KS, Karvinen KH, McNeely ML et al (2012) Predictors of adherence to supervised and unsupervised exercise in the Alberta physical activity and breast Cancer prevention trial. J Phys Act Health 9:857-866. https://doi.org/10.1123/jpah.9.6.857

29. Husebø AML, Karlsen B, Allan H, Søreide JA, Bru E (2015) Factors perceived to influence exercise adherence in women with breast cancer participating in an exercise programme during adjuvant chemotherapy: a focus group study. J Clin Nurs 24:500-510. https://doi.org/10.1111/jocn.12633 
30. Kampshoff CS, van Mechelen W, Schep G, Nijziel MR, Witlox L, Bosman L, Chinapaw MJM, Brug J, Buffart LM (2016) Participation in and adherence to physical exercise after completion of primary cancer treatment. Int J Behav Nutr Phys Act 13:100. https://doi.org/10.1186/s12966-016-0425-3
Publisher's note Springer Nature remains neutral with regard to jurisdictional claims in published maps and institutional affiliations. 